\title{
Varieties of Digital Work
}

\author{
Esther Ruiz Ben, Technische Universität Berlin, Germany
}

\begin{abstract}
In this article I develop a typology of digital work forms. Moving beyond the numerous conceptualisations of digital work, too focused on virtual work and neglecting material and invisible forms of digital work, I argue that to understand the global, interconnected varieties of digital work, it is necessary to apply a relational perspective that situates different forms of work and their linkages at the centre of the analysis. I propose a typology based on the relation to the process of work digitalisation. Further, I explain the linkages between various forms of digital work through the global exchange of tasks, materials and expertise resources. The typology serves as a heuristic tool for considering the broader implications of digitalisation for work and employment in terms of control and coordination as well as regulation and classification between linked workspaces, which I show using the example of the varieties of digital work needed to enable the use of smartphones.
\end{abstract}

\section{KEYWORDS}

Digital work; globalisation; virtual work; digitisation; Total Social Organisation of Labour

\section{Introduction}

In this article I suggest a conceptualisation of varieties of digital work evolving in adjacent ecologies of globally linked work. Several disciplines utilise particular forms of digital work and, as a result, many divergent definitions of these phenomena coexist, for example: digital labour (Scholz, 2013; immaterial labour (Hardt and Negri, 2000); playbour (Kücklich, 2016); platform work (Florisson and Mandl, 2018); crowd work (De Stefano, 2016). These different conceptualisations of digital work mostly focus on work carried out using information and telecommunication technologies (ICT). They tend to neglect the work needed for digitising information, and the tasks of extracting materials for digital devices and the manufacturing or logistics taking place internationally and frequently out of sight of virtual workers and consumers of those devices. Also, the relations between different forms of globally dispersed digital work are too focused on firms rather than on work agency.

In this article I refer to digital work as work carried out for, and using, ICT. I differentiate between three forms of digital work (see Table 1): (1) virtual work (enabled via the Internet), (2) digitalised work, (work that is standardised and partially substituted through digitisation), and (3) work for digitalisation (enabling virtual work and producing digitised work). This third form - work for digitalisation - is necessary for the functioning and governance of the Internet, and includes work involved in the logistics, manufacturing and waste disposal of devices and infrastructures that are necessary for using the Internet. Note that I also distinguish between digitisation as the process of moving information from analogue to digital formats, which can then be analysed using computers, 
and digitalisation as a process by which digital computer methods and technologies are applied in social, cultural, economic and industrial domains. The three varieties of digital work will be further explained in the two following sections.

Table 1: Overview of the three forms of digital work

\begin{tabular}{|l|l|}
\hline & Main Characteristics \\
\hline Virtual Work & Mediated/enabled by the Internet \\
\hline Digitised Work & Automated work using digital methods and technologies \\
\hline $\begin{array}{l}\text { Work for Digitalisation and } \\
\text { Digitisation }\end{array}$ & Supports the existence of virtual and digitised work \\
\hline
\end{tabular}

In contrast to these forms of digital work, non-digital work may also use digital technologies as supporting tools, but not primarily as essential tools to complete tasks. Examples include farmers' work that applies GPS technologies to tractors in the fields, or educational activities using "interactive" whiteboards. The distinctive characteristic of the varieties of digital work is that they use digital methods, tools and platforms not just as instruments that aid in the completion of tasks, but as essential, integrative parts of work exchange. ${ }^{1}$

These different forms of digital work are globally interrelated through work practices (including mobility) and expertise exchange in space and time, although some tasks remain invisible to each other through spatial, social and time mechanisms. ${ }^{2}$ Many scholars (such as Gereffi, 2014) have examined some forms of digital work from a spatial socioeconomic perspective using the concept of global value chains. However, work agency and invisible work are frequently neglected as are the interconnections of expertise between the different forms of globally dispersed work. I argue that to understand the global, interconnected varieties of digital work, it is necessary to apply a relational perspective that situates work forms and their interconnections at the centre. To achieve this, it is necessary to examine the linkages between tasks and organised actions of work digitalisation demarcated by employers, governments, workers and consumers. We can attempt to understand the demarcations by employers and governments by their definition and categorisation of tasks, as well as through allocation of work and the ways in which mobility is supported or hindered. Demarcations by workers and consumers can be understood by looking at their work practices from spatial and temporal perspectives.

To build the conceptualisation of varieties of digital work I suggest a heuristic for this preliminary analysis of the relation between digitalisation and the global dispersion of work. ${ }^{3}$ For

\footnotetext{
${ }^{1}$ The case of mining work carried out to source rare earth constitutes an exception. It does not use digital methods, tools or platforms, but supports the existence of digital infrastructures.

${ }^{2}$ Hatton (2017: 337) "defines 'invisible work' as labour that is economically devalued through three intersecting sociological mechanisms - here identified as cultural, legal and spatial mechanisms of invisibility - which operate in different ways and to different degrees".

${ }^{3}$ I define heuristics devices as "any procedure which involves the use of an artificial construct to assist in the exploration of social phenomena" (Scott and Marshall, 2014: 305). These devices are useful for conducting preliminary explorations of a topic. However, I acknowledge that, with their limitations as static
} 
this I use the concept of the Total Social Organisation of Labour (TSOL) elaborated by Miriam Glucksmann (2009). This concept helps us to understand the connections between different forms of digital work in globally dispersed work areas. Glucksmann's ideas reveal how connections are institutionalised and contested, including non-visible relations and power inequalities established through economic and social processes (Hatton, 2017).

In summary, bringing Glucksmann's ideas to the case of digital work I focus on the different actors and tasks, as well as their internationally dispersed links, to differentiate three types of digital work. Virtual work, digitised work and work for digitalisation can be conceptualised as adjacent work areas linked by tasks and actors' expertise and with different timings in work digitalisation. For example, the infrastructures for connecting hardware devices, as well as the institutional and regulating bases, are deployed before individual hardware devices to enable virtual work to be commercialised. The spaces materially connected through broadband infrastructures must have been previously produced in order to enable practices of virtual work or digitalised work (labour substitution) to follow. The actors in these adjacent types of work are globally connected beyond companies' boundaries.

The article is structured in four parts. In the first part I explain the definition of digital work, in order to build, in the second part, a typology of varieties of digital work. In the third part of the article, I explain the relations between the suggested varieties of digital work as possible heuristics for empirical research, using the example of the work needed to produce and use a smartphone. In the fourth part, I discuss the possibilities of applying the concept in further empirical research.

\section{Definition of Digital Work}

Digital work comprises many different tasks and forms of work. Scholz (2013), using the term "digital labour", points out that it is a continuation of social relations surrounding traditional workplaces, and that the shift of labour markets to the Internet intensifies challenges to traditional economies, such as of unpaid work, lack of minimum wages and absence of health insurance. Some forms of digital work also include unwaged work that does not appear to be labour at all - for example, selling customers' data or spreading advertisements in social media using customers as producers; Kücklich (2016) refers to this as "playbour". The added value of some digital labour is made with user participation, as work that is unpaid and freely given, in contrast to employment based on contractual relations. This is the case for the form of digital work labelled "crowd sourcing". In this model, outsourcing models of labour merge with digital networks' crowds (Scholz, 2013).

Digital work is not only taking place in what is perceived as the "immaterial Internet", but also in internationally offshored workplaces where work is enabled through the Internet. As research on platform work and crowd work reveals, this includes work performed in coordination with digital platforms such as Deliveroo and Ubereats, as well as within digital systems of labour market matchmaking such as TaskRabbit and Uber (De Stefano, 2016; Kenney and Zysman, 2016; Srnicek, 2016; Pais, 2020). The material infrastructures and devices needed to use the digital technologies involve work that very frequently happens in countries where wages are low. Working conditions in these countries are often more precarious than in countries where specialised valuecreating tasks take place, such as digital design and content production. Huws (2012: 3) has defined

ideal templates of reality, they do not provide a clear scope of the complex dynamics involved in the development and establishment of varieties of digital work. 
"virtual work" as "labour, whether paid or unpaid, that is carried out using a combination of digital and telecommunication technologies and/or produces content for digital media".

In contrast, I refer to digital work in the ways described in the Introduction. These different forms of digital work are interrelated in digitalisation processes through tasks and knowledge exchange in space and time. My argument is that to understand each of these types of digital work, it is necessary to apply a relational perspective of digitalisation processes that includes differences in knowledge and expertise as well as visible and invisible forms of work, logistics and recycling work related to the digital devices. These interrelations produce timing or sequences as well as particular spaces and territories. I conceptualise this as topographies of digital work. In contrast to dominant concepts of the global dispersion of work, such as the notion of global value chains which focus on firms as the main actors in the global economy, I put work at the centre of the definition of digital work, and workers and consumers as active actors who contribute to the global digitalisation of work.

Research about digital work has mostly focused on virtual forms of digital work, particularly on call centres, crowdsourcing and platform work (De Stefano, 2016; Kenny and Zysman, 2016; Srnicek 2016). The extensive current research on this last phenomenon has focused attention on the importance of global outsourcing of tasks and microtasks, and on the theories of the division of labour, among others Glucksmann's (2009) concept of the Total Social Organisation of Labour (Pais, 2020). However, the relations between different forms of work related to digitalisation remain unexplored, leaving many necessary types of work for digitalisation in the shadows.

The concept of digital work that I propose needs an understanding of the spaces and the dynamics of the various forms of digital work, but also a conceptualisation of the differences and connections between the forms of work taking place in adjacent work areas. Glucksmann's (1995, 2009) concept of the Total Social Organisation of Labour can help in understanding the connections between different forms of digital work. She differentiates between various ways of looking at labour. One is the classic division of labour, which she distinguishes from various socioeconomic institutional domains. The latter is what she refers to as the Total Social Organisation of Labour; it consists of market and nonmarket, formal and informal, paid and unpaid labour. She also discusses instituted economic processes (IEP), including the work that consumers must do to be able to purchase goods, thus completing the economic process (Glucksmann, 2009: 884).

The three forms of work that I introduced earlier in this article can be seen as three different specialisations in terms of Glucksmann's typology; they comprise interconnected work modes (paid, unpaid, voluntary, etc.) along instituted economic processes of labour including consumption work. TSOL of digital work is supported by algocratic forms of governance which constitute a form of work for digitalisation (Just and Latzer, 2017). Consumption work that is devoted to, for example, installing digital devices, is needed to complete instituted economic processes of digital work. The three forms of digital work can be analysed along Glucksman's labor dimensions as I show in the following sections. Glucksmann's ideas reveal how connections are institutionalised and contested, including non-visible relations established through economic processes. In the next section I build a typology of digital work based on the relations of tasks to digitalisation 


\section{Towards a Typology of Digital Work}

\section{Virtual work}

Virtual work is understood as work taking place on the Internet and mediated by online technologies that are used to organise work - dislocating, redistributing and relocating it. It is a form of work characterised as dematerialised, though not "hermetically sealed", from the rest of the economy (Webster and Randle, 2016: 5). This type comprises many different forms of work and in the recent years a rapid growth of new tasks (paid and unpaid) has emerged, due to the expansion of the Internet and the blurring of boundaries between workplaces, as well as between work and consumption. For example, Internet users generate content as open-source or shareware contributors, but also by building websites, modifying software, participating in mailing lists or building virtual spaces (Terranova, 2004). Virtual work is characterised by its immateriality. This feature began to be researched during the 1990s, in relation to the development and usage of ICT.

The Internet has expanded to almost every economic sector and has become an integral part of social life in many countries, also enabling digitalisation processes of formerly dispersed economic areas. This rapid and extensive diffusion of the Internet has also led to the inclusion of online volunteer labour as a new form of work, as alternative resistance to conventional wage labour, for example in social enterprises (Fish and Srinivasan, 2012), in online activist campaigns (Tatarchevskiy, 2011), in non-profit organisations (Mook, Handy and Quarter, 2007), or as "commons-based peer production" (Benkler and Nissenbaum, 2006, Qiu, Gregg and Crawford, 2014). Moreover, the diffusion of the Internet has allowed not only a permanent connection of distant workplaces around the world, but also the substitution of labour itself through digitisation.

\section{Digitised work}

My notion of digital work includes the work involved in the digitisation of work itself - that is, work for digitalisation. This is the work needed, for example, for automating manufacturing using digital tools, infrastructures and methods, and the bureaucracy that activates a dynamic of digitalised work in multiple areas of the labour market and geographical locations (Ruiz Ben, 2018). Automation is a phenomenon that has been occurring for a long time in some economic sectors such as car production plants (Keynes, 1930). However, with the development of digital tools and online digital infrastructures enabling the availability of big data, automation processes have expanded to many others economic sectors. In recent years, a very controversial debate was initiated by the publication of results from research estimating the risks of automation through digitalisation (Frey and Osborne, 2013). This research shows that 47 per cent of jobs in the United States are at high risk of digital automation within two decades. Since the publication of these estimates, the research has been replicated in other industrialised and developing economies and reveals similar, if not more dramatic, risks of digital automation in certain occupations (Chang and Huynh, 2016). Frey and Osborne (2013) predict that nearly every occupation can be digitally automatised in the future. The only exceptions to this process are those tasks involving a high amount of creative intelligence, social intelligence and perception skills. Precisely these three features constitute the basis of Frey and Osborne's estimations of automation risks. They codify the probability of an occupation's automation in terms of the extent to which the occupation requires these three non-automatable skills. Some scholars have further developed Frey and Osborne's research methodology and interpretations (Collins, 2013; Brynjolfson and McAfee, 2014; Pistono, 2014; Pupo, 2014; Brandes and Wattenhofer, 2016). 
Brandes and Wattenhofer (2016: 1) show a strong negative correlation between the level of education required for a job and its probability of being automated. Pfeiffer and Suphan (2015) criticise Frey and Osborne's perspective from another angle. They contend that the distinction between routine and non-routine tasks, on which the automation risks are based, is too simplistic. Pfeiffer and Suphan (2015) suggest the necessity for a deeper understanding of experience as a fundamental feature of work. They elaborate an alternative methodology for analysing the risks of digitalisation focusing on the case of Germany and departing from the assumption that the risk of automation relies on whether workers have the capacity for coping with unpredictability and complexity; such an approach grounds risk not only in education, but also in work experience crystallised in living labour capacity. Pfeiffer and Suphan's (2015) research results show that 74 per cent of employees in Germany are competent to deal with complexity. The authors see appropriate vocational and academic continuing education programmes as key to overcoming possible risks of digital automation. But in the process of digitalisation, machines are also learning to deal with complexity, even from human experiences, using data designing as well as algorithmisation for defining tasks, risks and processes. These tasks gain importance and require an upgrading of skills that not every worker can manage, due to, for example, developing work habits over long periods or a lack of background qualifications.

Digitalisation processes also reduce uncertainty through the creation of a relatively predictable digital system of interactive learning machines with a long-term decreasing need for external human operation. One question would be how many workers are still necessary, and for how long, at a particular workspace in order to cope with the uncertainties and complexities that the created machine systems cannot foresee but might learn to manage. Thus, while in some work tasks will be objectified, digitally defined and absorbed, allowing labour to be substituted by machines, other tasks for enabling this digitalisation, requiring new skills and qualifications, emerge. I argue that a relational perspective of the dynamic destruction/creation of work and expertise, considering how digitisation and digitalisation affects the transformation of labour and knowledge as well as their spatial and temporal dimensions, is needed beyond predictions based on single and static characteristics of work.

Moreover, digitalisation also enables new forms of distant working and division of labour, reducing some costs. The utilisation of specialised skilled workers from other countries, with better skills and the flexibility to adapt their knowledge - due not least to the investment of multinational companies in the development of local universities in low-wage countries - has been occurring for decades in the form of offshoring in software development and hardware production (Ruiz Ben and Claus, 2005). Even if workers can cope with complexity, and if work can be spatially moved to lower-wage workspaces, digitalisation will support this development with long-term consequences for the international division of labour and the transformation of qualifications. This can be seen, for example, in the permanent lack of highly-skilled STEM ${ }^{4}$ workers in high-wage countries (Ruiz Ben, 2013).

Education and reskilling do constitute important aspects in the digitisation of work and the estimation of work substitution risks. However, these debates neglect the importance of digitisation itself (as well as related temporal and spatial dimensions) in the dynamic destruction/creation of work and skills. They also pay little attention to the transformation of living labour capacity. Because of the expansion of digital automation, new digitalisation tasks, skills requirements and ongoing work experiences emerge and are captured by algorithmisation (Shefstakofsky, 2017). This

\footnotetext{
${ }^{4}$ STEM $=$ science, technology, engineering and mathematics
} 
is the case, for example, for digital designers of Internet infrastructures, eGovernment and smart cities (in the private as well as public sector). Such designers are highly in demand in the labour market and difficult to find, not least because of the hybrid composition of the skills required. These kinds of tasks, emerging as a consequence of the digital automation of work, are included in the type of digital work that I call "work for digitalisation", which also comprises the "invisible" work of, for example, materials extraction or manufacturing, offshored to low-wage countries. In the next section I focus on this type of digital work.

\section{Work for digitalisation}

Work for digitalisation involves governance work through algorithmisation, but also forms of invisible work dispersed in low-wage countries. This invisible work includes, for example, the extraction of materials in some African countries, minerals that are necessary for launching infrastructures and producing hardware devices that enable the development of software (SHIFT, 2019: 28ff). Other examples include the manufacture of hardware devices taking place in some Asiatic countries, and consumption work undertaken by consumers to enable virtual work that they may be offered through crowd sourcing or as teleworkers (SHIFT, 2019: 36). Also included in the notion of work for digitalisation is work related to logistics and transportation of material goods for infrastructures, as well as to material goods offered on the Internet through virtual work. As many scholars assert, virtual work relies on and relates to manufactured commodities and physical infrastructures (Huws, 2014; Qiu et al., 2014; Dyer-Whiteford, 2015; Webster and Randle, 2016). Seen through the analytical lenses of Glucksmann's (2009) theoretical dimension of instituted economic process of labour, work for digitalisation can be conceived as production and distribution tasks. Additionally, governance tasks related to information assemblage, data designing and algorithmisation or infrastructure control must also be included, as they support exchange and post-exchange tasks of virtual work. Basically, an algorithm is a set of rules to be followed in problem-solving operations, frequently used in computing. Algorithms involve a particular vision of reality's problems and solutions, constructed by several actors with concrete interests and expectations. As a particular vision of reality and set of rules, algorithms gain agency in a limited, defined digital environment.

Moreover, algorithms can themselves be active as a structure, institution and even as actors (Dolata and Werle, 2007). ${ }^{5}$ Algorithms are constructed by cooperating actors and play an active role in linking and governing predefined activities (Shefstakofsky, 2017). They also play a role as institutions or governing instruments in these linked ecologies (Napoli, 2014; Just and Latzer, 2017). In this role, algorithms influence behaviours through rules and routines delimiting activities, while creating new and frequently uncertain agency possibilities. Precisely these uncertainties during the first innovation moments of the digitalisation of work are absorbed by algorithms and transformed in defined risks, creating learning sequences to reduce the "unexpected". This affects digitised work: reducing the unexpected is the first step towards automating work and in the long term making it more and more independent from human expertise by coping with unpredictability and complexity (Pfeiffer and Suphan, 2015). As several scholars remark, algorithms co-evolve with societal change (Shah and Kesan, 2011; Katzenbach, 2012; Just and Latzer, 2017). During the innovation process new tasks will emerge, but in which form, how they will be adapted and adopted in organisational settings, and for how long they remain in place is as uncertain as the geographical locations in which they will occur (Shefstakofsky, 2017).

\footnotetext{
${ }^{5}$ They can be actors in the sense that they can overtake and perform digital actions.
} 
The extent to which the expertise of experienced workers will still be required is also hard to predict, most of all in the case of disruptive innovations. Time and space are crucial dimensions in this process: from a short-term perspective, some jobs will be substituted by digital tools that in the long term will learn how to reduce uncertainties in work processes and thus potentially substitute even more jobs. At the same time, new jobs could be created by new skills demands including algorithmisation skills - to which workers will have to adapt their capacity to cope with unpredictability. From a space perspective, large multinationals invest in or set up educational institutions beyond national boundaries in order to create workforce reserves to confront the permanent shortage of highly skilled workers. This has been taking place in India, for example, since the 1990s (Aneesh, 2006). However, due to algorithmisation, this large demand could shrink, resulting in a new international division of labour (Ruiz Ben, 2013), restricting algorithmisation and digitalisation governance to multinational headquarters, while substituting programming tasks for work previously offshored to lower-wage countries.

Other forms of work for digitalisation - such as consumption work, extraction of materials for infrastructures and hardware, and e-waste management or recycling, as well as manufacturing of digital devices - are frequently taken for granted and mostly ignored in the theories of digitalisation of work. However, they are necessary for the functioning of virtual as well as digitised work. From Glucksmann's (2009) analytical perspective, they belong to the instituted economic process of labour. Whereas governance forms of work for digitalisation operate between the material and the abstract representation of work realities, these other forms of work for digitalisation are directly related to the material aspect of the work. They are tied to the material resources available at particular locations, except manufacturing which is relatively geographically mobile. Another invisible sort of work for digitalisation is recycling e-waste. In the production strategy of planned obsolescence of digital devices to accelerate growth in sales, recycling is not included as yet. Moreover, looking at recycling e-waste from Glucksmann's analytical perspective, work by consumers is also involved in this end-of-lifecycle of digital devices.

Manufacturing of hardware devices is also a form of work for digitalisation. It is mostly located in China, followed by other Asian countries where wages and work conditions are lower than in Western regions of the world (Lee and Gereffi, 2013). This form of work for digitalisation includes assembling components for hardware as well as for network connection, such as antennas for wireless telecommunication or cable manufacturing. Similar to the extraction, processing and recycling of materials for digital devices, these connected tasks are invisible to consumers of digital devices, to virtual workers and to those workers employed in governing tasks of work for digitalisation.

In the next section I show a brief example of how to apply the heuristics of the varieties of digital work to the case of the work needed to enable the use of smartphones.

\section{Application of the Typology to the Work Needed to Use a Smartphone}

Table 2 builds on the information given in Table 1, and provides an overview of some of the tasks corresponding to the varieties of digital work. This overview is a brief explorative approximation to show how the proposed heuristic could be empirically applied, in this case to the "work chains" related to the manufacture and use of a smartphone. The first two columns include the classification of the varieties of digital work, and the following three columns show the dimensions of Glucksmann's Total Social Organisation of Labour. 
Table 2: Application of the digital work typology to the work needed to use a smartphone

\begin{tabular}{|c|c|c|c|c|}
\hline & $\begin{array}{l}\text { Main } \\
\text { Characteristics }\end{array}$ & Division of Labour & $\begin{array}{l}\text { Total Social } \\
\text { Organisation of } \\
\text { Labour }\end{array}$ & $\begin{array}{l}\text { Instituted } \\
\text { Economic } \\
\text { Processes of } \\
\text { Labour }\end{array}$ \\
\hline Virtual Work & $\begin{array}{l}\text { Mediated or enabled } \\
\text { by the Internet }\end{array}$ & $\begin{array}{l}\text { Online sellers } \\
\text { Online resellers }\end{array}$ & $\begin{array}{l}\text { Private } \\
\text { Private }\end{array}$ & Trade/Exchange \\
\hline $\begin{array}{l}\text { Digitised } \\
\text { Work }\end{array}$ & $\begin{array}{l}\text { Automatised work } \\
\text { using digital methods } \\
\text { and technologies }\end{array}$ & $\begin{array}{l}\text { Automatised user } \\
\text { support } \\
\text { Automatic } \\
\text { assemblers }\end{array}$ & $\begin{array}{l}\text { Private } \\
\text { Private }\end{array}$ & $\begin{array}{l}\text { Trade/Exchange } \\
\text { Production }\end{array}$ \\
\hline $\begin{array}{l}\text { Work for } \\
\text { digitalisation } \\
\text { and } \\
\text { digitisation }\end{array}$ & $\begin{array}{l}\text { Supports the } \\
\text { existence of virtual } \\
\text { and digitised work }\end{array}$ & $\begin{array}{l}\text { Mine workers } \\
\text { Energy supply } \\
\text { Assemblers } \\
\text { IT usability designers } \\
\text { IT security experts } \\
\text { Telecommunication } \\
\text { engineers } \\
\text { High-street vendors } \\
\text { Installation } \\
\text { supporters/ } \\
\text { consumers } \\
\text { Call centre advisors }\end{array}$ & $\begin{array}{l}\text { Private } \\
\text { Private } \\
\text { Private } \\
\text { Private } \\
\text { Private } \\
\text { Private/public } \\
\text { Private } \\
\text { Private/voluntary/ } \\
\text { consumption work } \\
\text { Private }\end{array}$ & $\begin{array}{l}\text { Production } \\
\text { Production } \\
\text { Production } \\
\text { Production } \\
\text { Production } \\
\text { Production } \\
\text { Trade/exchange/ } \\
\text { consumption } \\
\text { Trade/exchange/ } \\
\text { consumption }\end{array}$ \\
\hline
\end{tabular}

\section{Virtual work}

In the case of smartphones, virtual work includes work taking place on the Internet for online selling and reselling of the whole range of products related to smartphones (including hardware such as audio accessories and power-related accessories, adjunct devices such as wearables and smart speakers, as well as content in the form of applications and support services). These forms of work are, from Glucksmann's perspective, private tasks in a trade/exchange mode.

\section{Digitised work}

In the case of smartphones, digitised work tasks are those that are automated and dedicated to user support; these tasks are private and in the area of trade/exchange. Moreover, some assembling tasks in the area of production are automated and have a private nature. These tasks can take place 
in Asian countries, substituting manual assembling corresponding to work for digitalisation (SHIFT, 2019: 36).

\section{Work for digitalisation and digitisation}

This form of digital work comprises a whole range of tasks aiding virtual and digitised work. In production it comprises private modes of work in materials extraction and processing, energy supply, design, manual assembling and private/public ICT engineering. In trade/exchange, highstreet vendors sell the devices directly to consumers through private businesses. Installation of smartphones includes private and invisible voluntary work directly accomplished by the users (consumption work) or by voluntary supporters (friends, relatives).

In the case of materials extraction for hardware devices, including materials for the production of smartphones, the so-called rare-earth elements (REEs) are used for the supposedly "clean" and immaterial digital industry. The production, use and recycling of these REEs can create international labour disparities, but also environmental and health costs in places as distant as mines in California and e-waste recycling villages in China (Levy, Meisneer and Iles, 2017). REEs consist of the fifteen lanthanide metals plus scandium and yttrium (US EPA, 2012; Levy et al., 2017). The powerful magnetic properties of these materials enable the further development of miniaturisation of digital devices and increases in battery and screen efficiency (Marscheider-Weidemann et al., 2016). REEs must be processed and purified for use in digital devices. The United States, China and South Africa are the principal extraction locations for REEs used in digital devices. China is currently the main extractor of REEs in the world (US EPA, 2012). Extraction and refinement of REEs has significant negative environmental implications which can be seen in the Mojave Desert in California or in Inner Mongolia in China (Levy et al., 2017). Moreover, it is estimated that 40 per cent of REE extraction work in China is illegal, outside the control of the government and without working-condition standards (Levy et al., 2017). Plans for extracting REEs in other countries, as well as reducing extraction through recycling, are on the rise, and a shift in the global division of work for digitalisation is expected (Levy et al., 2017).

Recycling constitutes another invisible form of material work for digitalisation. Most obsolescent digital devices, including smartphones, are imported as e-waste by India, China and Nigeria, among others, where recycling work occurs without any protection and with devastating health consequences (Iles, 2004; Grant et al., 2014). Recycling also involves consumption work; that is, consumers contribute to the recycling process by bringing the devices to e-waste collection points for recycling.

In the next section I focus on the relation between digitalisation and the dispersion of work, including the socio-spatial mechanisms of invisibility of some forms of digital work.

\section{Discussion and Conclusion}

In the previous pages I have suggested a conceptualisation of global varieties of digital work moving beyond conceptualisations of virtual work that are too focused on immaterial tasks taking place on the Internet, and on theories of global economies that concentrate on firms' activities and neglect work agency. Departing from Glucksmann's (2009) Total Social Organisation of Labour, I have distinguished three forms of digital work differentiated by their relation to the process of work digitalisation and linked through the global exchange of tasks, materials and expertise resources. I understand digitalisation as a process by which digital computer methods and 
technologies are applied in social, cultural, economic and industrial domains.

In the typology that I propose, digital work comprises three main varieties: virtual work, digitised work and work for digitalisation. Virtual work is the work taking place on the Internet, mediated by online technologies that are used to organise work - dislocating, redistributing and relocating it. A common feature of virtual work is its immateriality, as it takes place on the Internet. Digitised work is work that is automated using digital tools, infrastructures and methods. Lastly, work for digitalisation is the work needed to enable the other two forms. It involves governance work through algorithmisation, but also includes forms of invisible work dispersed in low-wage countries or precarious areas of the global labour market. It is necessary for launching infrastructures and producing hardware devices, logistics and transportation of material goods for infrastructures, but also for consuming and recycling digital devices. From the perspective of the Total Social Organisation of Work (Glucksmann, 2009), I have argued that these forms of digital work can be seen as three different specialisations (or divisions of labour) of work digitalisation that include interconnected work modes (paid, unpaid, voluntary, invisible, etc.) along instituted economic processes of labour, including consumption work. The divisions are not exclusive. Each type acts as a (flexible) surround for others, linked through several and changing linkages, as I have explained for the smartphone case, for example. The spatial natures of the three forms of digital work are not exclusive and might change, as the movement of manufacturing of digital devices from China to Vietnam shows (Zhong, 2019; Bursztynsky, 2020; Reuters, 2020).

Also, expertise can change from one form of digital work to another, and can affect the formations of work areas, as it is the case with the specialisation of algorithmisation for particular economic segments (e.g., automotive) or even public services (e.g., big data usage for smart cities). In some cases, expertise expands (as in the case of algorithmisation for governance) and in others it concentrates and specialises in a particular settlement or is delegated to digital devices (automation) or even to consumers/citizens once a part of the service work is automatised (e.g., consumers' forums for broadband support or online banking, online tax declarations, online support in call centres). This dynamic affects the economic modes in which the varieties of digital work are organised, as is the case, for example, with the delegation of tasks and expertise for supporting the installation of broadband or smartphones to consumers' forums, changing support services from paid work offered in a company to unpaid informal work offered by consumers. Workers themselves contribute to the shifting of economic modes, offering their work in numerous forums or, as is the case with crowd working, for a symbolic amount of money, making some services obsolete and destroying paid work. Workers, as well as companies, build ties between tasks and organised action of globally dispersed work through their mobility via geographical migration or occupational trajectories, which can evolve to a momentary specialisation in a certain location in the process of global digitalisation of work.

The concept of varieties of digital work can be used as a heuristic for empirical analysis in different ways. One example has been shown above. Moreover, it could help to analyse how particular forms of digital work emerge or share certain tasks. Another possible empirical application is looking at how digital work affects changes in expertise in specific economic sectors, leading to specialised digitised work or to algorithmisation work, for example in the automotive sector. The framework proposed can also be used to analyse how workers move out of or stay in specific areas of expertise and work, and to inquire into their expectations and motivations about work digitalisation and their places to work and live.

In sum, the concept of the varieties of digital work enables the analysis of interconnections and dynamics of labour, moving beyond other approaches that are too focused on companies and 
organisations and leave aside work agency. Companies are an important actor in the digitalisation of work, making decisions about locations of work, setting rules and providing resources for careers, for example, However, workers/consumers/citizens are crucial actors in this process as well, and are frequently neglected in the literature about global economies. Thus, the approach of global varieties of digital work contributes to the development of a better understanding of the digitalisation of work and its relation to the global dispersion of work.

\section{References}

Aneesh, A. (2006) Virtual Migration: The Programming of Globalization. Durham, NC: Duke University Press.

Benkler, Y. and H. Nissenbaum (2006) Commons-based Peer Production and Virtue. Journal of Political Philosophy, 14(4): 394-419.

Brandes, P. and R. Wattenhofer (2016) Opening the Frey/Osborne Black Box: Which Tasks of a Job are Susceptible to Computerization? https://arxiv.org/pdf/1604.08823.pdf (accessed 24 August 2017).

Brynjolfson, E. and A. McAfee (2014) The Second Machine Age: Work, Progress, and Prosperity in a Time of Brilliant Technologies. New York and London: W.W. Norton \& Co.

Bursztynsky, J. (2020) Apple is Reportedly Starting to Build Some of its AirPods in Vietnam. https://www.cnbc.com/2020/05/08/apple-airpods-being-built-in-vietnam---report.html (accessed 1 June 2021).

Chang, J-H. and P. Huynh (2016) Asean in Transformation. The Future of Jobs at Risk of Automation. ILO Working Paper No. 9. Geneva: International Labour Organization, Bureau for Employers' Activities, Regional Office for Asia and the Pacific.

Collins, R. (2013) The End of Middle Class Work: No More Escapes. In Does Capitalism Have a Future? edited by I. Wallerstein, R. Collins, G. Derlugian and C. Calhoun. Oxford and New York: Oxford University Press.

De Stefano, V. (2016) The Rise of the "Just-in-Time Workforce": On-Demand Work, Crowdwork and Labour Protection in the "Gig-Economy". Comparative Labour Law \& Policy Journal, 37: 471-504.

Dolata, U. and R. Werle (2007) Bringing Technology Back In. In Gesellschaft und die Macbt der Technik, edited by U. Dolata and R. Werle. Frankfurt: Campus Verlag.

Dyer-Witheford, N. (2015) Cyber-proletariat: Global Labour in the Digital Vortex. London: Pluto Press.

Fish, A. and R. Srinivasan (2012) Digital Labor is the New Killer App. New Media \& Society, 14(1): 137-152.

Florisson, R. and I. Mandl (2018) Platform Work: Types and Implications for Work and Employment: Literature Review. Dublin: Eurofound.

Frey, B. and M.A. Osborne (2013) The Future of Employment: How Susceptible Are Jobs to Computerisation? Paper presented to the "Machines and Employment Workshop", Oxford Martin Programme on the Impacts of Future Technology, University of Oxford, 17 September 2013. https://www.oxfordmartin.ox.ac.uk/ downloads/academic/The Future of Employment.pdf (accessed 3 October 2017).

Gereffi, G. (2014) Global Value Chains and Upgrading: Implications for Food and Nutrition Security. https://www.centrorossidoria.it/wp-content/uploads/2016/01/Gereffi GVCs-andUpgrading.pdf (accessed 20 October 2017).

Glucksmann, M. (1995) Why Work? Gender and the 'Total Social Organization of Labour. Gender, Work and Organisation, 2: 63-75.

Glucksman, M (2009) Formations, Connections and Divisions of Labour. Sociology, 43(5): 878-895.

Grant, K., F. Goldizen, P. Sly and M. Brune (2014) Health Consequences of Exposure to e-Waste: A Systematic Review. Lancet Global Health, 1(6): e350-e361. 
Hardt, M. and A. Negri (2000) Empire. Cambridge, MA: Harvard University Press.

Hatton, E. (2017) Mechanisms of Invisibility: Rethinking the Concept of Invisible Work. Work, Employment and Society, 31(2): 336-351.

Huws, U. (2012) Technical Annex to Memorandum of Understanding for EU COST Action on the Dynamics of Virtual Work. Brussels: EU COST Secretariat.

Huws, U. (2014) Labor in the Global Digital Economy. The Cybertariat Comes of Age. New York: Monthly Review Press.

Iles, A. (2004) Mapping Environmental Justice in Technology Flows. Global Environmental Polity, 4(4): $76-$ 107.

Just, N. and M. Latzer (2017) Governance by Algorithms: Reality Construction by Algorithmic Selection on the Internet. Media, Culture \& Society, 39(2): 238-258.

Katzenbach, C. (2012) Technologies as Institutions. In Trends in Communication Policy Research, edited by N. Just and M. Puppis. Bristol: Intellect.

Kenney, M. and J. Zysman (2016) The Rise of the Platform Economy. Issues in Science and Technology, 32(3): 61-69.

Keynes, J.M. (1930) Economic Possibilities for our Grandchildren. In Essays in Persuasion, edited by J.M. Keynes. New York: Harcourt Brace.

Kücklich, J. (2016) Precarious Playbour: Modders and the Digital Games Industry. http:// five.fibreculturejournal.org/fcj-025-precarious-playbour-modders-and-the-digitalgames-industry (accessed 3 November 2017).

Lee, J and G. Gereffi (2013) The Co-evolution of Concentration in Mobile Phone Global Value Chains and Its Impact on Social Upgrading in Developing Countries. Captuirng the Chains Working Paper 25. http://www.capturingthegains.org/pdf/ctg-wp-2013-25.pdf (accessed 27 October 2017).

Levy, S., R.C. Meisner and A. Iles (2017) Mapping the Product Life Cycle: Rare Earth Elements in

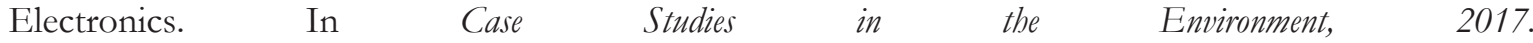
http://cse.ucpress.edu/content/ecs/early/2017/09/21/cse.2017.000265.full.pdf (accessed 12 November 2017).

Marscheider-Weidemann, F., S. Langkau, T. Hummen, L. Erdmann and L. Tercero Espinoza (2016) Rohstoffe für Zukunftstechnologien -Berlin. https://www.deutscherohstoffagentur.de/DERA/DE $\angle$ Downloads/Studie Zukunftstechnologien2016.pdf? blob=publicationFile\&v $=3 \quad$ (accessed 12 September 2017).

Mook, L., F. Handy and J. Quarter (2007) Reporting Volunteer Labor at the Organizational Level: A Study of Canadian Nonprofits. Voluntas: International Journal of Voluntary and Nonprofit Organizations, 18(1): 5571.

Napoli, P.M. (2014) Automated Media: An Institutional Theory Perspective on Algorithmic Media Production and Consumption. Communication Theory, 24(3): 340-360.

Pais, I. (2020) Digital Platforms and the Transformations in the Division of Labor. In Handbook of Labor, Human Resources and Population Economics, edited by K.F. Zimmermann. Berlin: Springer.

Pfeiffer, S. and A. Suphan (2015) Der AV-Index. Lebendiges Arbeitsvermögen und Erfahrung als Ressourcen auf dem Weg zu Industrie 4.0. Working Paper 2015 \#1, Universität Hohenheim, Fg. Soziologie. http://www.sabine-pfeiffer.de/files/downloads/2015-Pfeiffer-Suphandraft.pdf (accessed 12 July 2017).

Pistono, F. (2014) Robots will Steal your Job but that's Ok. How To Survive the Economic Collapse and be Happy. Second edition. Los Angeles: CreateSpace Independent Publishing Platform.

Pupo, A. (2014) Cognitivity Everywhere: The Omnipresence of Intelligent Machines and the Possible Social Impacts. World Future Review, 6(2): 114-119.

Qiu, J.L, M. Gregg and K. Crawford (2014) Circuits of Labour: A Labour Theory of the iPhone Era. tripleC, 
12(2): 564-581.

Reuters Staff (2020) Samsung to Relocate Chinese Display Production to Vietnam. Reuters, 19 June 2020. https://www.reuters.com/article/vietnam-samsung-idUSL4N2DW2CV (accessed 1 June 2021).

Ruiz Ben, E. (2013) Internationale Professionalität: Transformation der Arbeit und des Wissens in transnationalen Arbeitsfeldern. Berlin: Springer.

Ruiz Ben, E. (2018) Intersectionality in the Practice of Mixed Methods Gender Research. Journal of Research in Gender Studies, 8(1): 73-88.

Ruiz Ben, E. and R. Claus 2005 Offshoring in der deutschen IT Branche. Informatik Spektrum, 28(1): 34-39.

Scholz, T. (2013) Digital Labor. The Internet as Playground and Factory. London: Routledge.

Scott, J. and G. Marshall (2014) A Dictionary of Sociology. Oxford, UK: Oxford University Press.

Shah, R. and J. Kesan (2011) Software as Governance. http://papers.ssrn.com/abstract=1799431 (accessed 17 October 2017).

Sheffstakofsky, B. (2017) Working Algorithms: Software Automation and the Future of Work. Work and Occupations, 44(4): 376-423.

SHIFT (2019) Wirkungsbericht. https://www.shiftphones.com/downloads/SHIFT-wirkungsbericht-201905-10.pdf (accessed 17 February 2021).

Srnicek, N. (2016) Platform Capitalism. Hoboken, Hoboken, NJ: Wiley.

Tatarchevskiy, T (2011) The "Popular" Culture of Internet Activism. New Media \& Society, 13(2): 297-313.

Terranova, T. (2004) Network Culture: Politics for the Information Age. London: Pluto Press.

United States Environmental Protection Agency (US EPA) (2012) Rare Earth Elements: A Review of Production, Processing, Recycling, and Associated Environmental Issues. Report EPA 600/R-12/572. Cincinnati, OH: EPA. http://neis.epa.gov/Adobe/PDF/P100EUBC.pdf (accessed 15 October 2017).

Webster, J. and K. Randle (eds.) (2016) Virtual Workers and the Global Labour Market. London: Palgrave Macmillan.

Zhong, R. (2019) Your Next iPhone Might Be Made in Vietnam. Thank the Trade War. New York Times, 30 July 2019.

\section{BIOGRAPHICAL NOTE}

Esther RuIz BEN completed her PhD in Sociology at the Facultad de Ciencias Políticas y Sociología at the Universidad Complutense de Madrid, and her habilitation at the Technische Universität Berlin. She also has a Bachelor in Computer Science from the University of Applied Sciences in Berlin (HTW). Esther has a long international research experience in areas such as the internationalisation and digitalisation of work, the development of electronic government and the digital transformation of urban areas (smart cities and regions). Currently, she is conducting research about usable privacy and security of digital public services funded by the German Federal Ministry of Justice and Consumer Protection. [Email: esther.ruiz-ben@,campus.tu-berlin.de; esther.ruiz-ben@posteo.net] 